\title{
Obtenção de substância surfactante a partir da modificação de celulose
}

\author{
Obtaining a surfactant substance through cellulose modification
}

\author{
C. M. R. Santos; D. C. S. da Graça; G. Cardoso \\ Departamento de Engenharia Química /Laboratório de Desenvolvimento e caracterização/Universidade Federal de \\ Sergipe ,49100-000,São Cristóvão-SE, Brasil
}

e-mail: cleciosantos-1@hotmail.come giselia@ufs.br

(Recebido em 31 de janeiro de 2016; aceito em 13 de julho de 2016)

\begin{abstract}
A atenção mundial aos problemas ambientais tem motivado, nas últimas décadas, estudos sobre a produção de substâncias oriundas da biomassa, por esta ser uma matéria-prima de fonte renovável e seus derivados apresentarem baixo impacto ambiental. Dentre as substâncias extraídas da biomassa, a celulose tem tido destaque e emprego potencial em diversas aplicações, pois a sua estrutura pode ser modificada originando produtos com diferentes propriedades de uso industrial. Este estudo teve por objetivo desenvolver uma rota tecnológica para a obtenção de substância surfactante de sisal (Agave sisalana) modificado com álcool láurico, a partir de xantato celulósico. O produto obtido foi caracterizado quimicamente por espectroscopia na região do infravermelho com transformada de Fourier (FT-IR) quanto à inserção do modificante na macromolécula celulósica e os resultados da referida análise mostraram que o processo de modificação empregado foi efetivo. Análises de verificação da capacidade de dissolução e do grau de saponificação do novo produto, em meio aquoso, mostraram que o processo realizado conferiu boa dispersão e baixo grau de saponificação. O caráter anfifílico da celulose modificada, associado ao baixo grau de saponificação, lhes conferiu atributos para uso em processos industriais.

Palavras chave: Celulose; modificação; surfactante.
\end{abstract}

The world's attention to environmental problems has motivated, in recent decades, studies on production of substances derived from biomass, since it is a renewable source and its derivatives present low environmental impact. Among the substances extracted from biomass, the pulp it has had highlighted, and use in various applications, because its structure can be modified giving products with different properties for industrial use. This study aimed to develop a technological route to getting sisal surfactant substance (Agave sisalana) modified with lauryl alcohol from cellulose xanthate. The product obtained was chemically characterized by spectroscopy in the infrared Fourier transform (FT-IR) for the insertion of the modifier in the cellulosic macromolecules and the results of this analysis show that the process of modification employed was effective. Analysis testing of the capacity dissolution and the degree of saponification of the new product in an aqueous medium, the process performed showed that gave good dispersion and low degree of saponification. The amphiphilic character of the modified cellulose, together with the low degree of saponification gave them attributes for use in industrial processes.

Keywords: cellulose; modification; surfactant.

\section{INTRODUÇÃO}

A celulose é uma substância existente em grande quantidade nas plantas e que vem sendo utilizada de diversas formas há séculos pelo homem, principalmente na forma de fibras, goma, e na produção de papel. Contudo, nas últimas décadas, a celulose vem sendo modificada quimicamente com o intuito de produzir novos materiais e substâncias aditivas para processos industriais, visando substituir produtos de uso convencional, advindos de derivados de petróleo [1-5].

Do ponto de vista bioquímico, a celulose é um polissacarídeo que se apresenta como um polímero de cadeia linear com um comprimento suficiente para torná-la insolúvel em solventes orgânicos, água, ácidos e álcalis diluídos, à temperatura ambiente, consistindo única e 
exclusivamente de unidades de $\beta$-D-anidroglucopiranose, que se ligam entre si através dos carbonos 1-4, possuindo estrutura organizada e parcialmente cristalina [6,7].

A estrutura molecular confere a celulose propriedades características tais como: hidrofilicidade, degradabilidade e ampla variedade química conferida pela alta reatividade dos grupos hidroxila. Sendo estes grupos a base para extensas redes de ligações de hidrogênio, o que confere a celulose uma estrutura parcialmente cristalina e diferentes formas. A sua reatividade é governada pela presença na estrutura molecular de grupos hidroxilas que podem reagir por mecanismo de adição, substituição e oxidação; grupos acetais que podem sofrer hidrólise tanto em meio ácido como em meio alcalino e grupos aldeídicos terminais que podem ser reduzidos a grupos álcoois, que oxidados se transformam em grupos carboxilicos, ou, quando na presença de álcali, se rearranjam para formar grupos terminais alcoólicos ou carboxílicos. As reações químicas mais importantes da celulose são as reações de adição, as reações de substituição e reações de quebra das ligações glucosídicas (degradação da celulose) [8,9].

$\mathrm{O}$ rompimento das ligações glucosídicas ocorre entre os monômeros de glucose. Esse rompimento depende das condições físicas do processo reativo e pode se estender por parte da cadeia de celulose, daí porque a reação muitas vezes ser denominada de reação de degradação da celulose. Em geral, os rompimentos das ligações glucosídicas levam à formação de moléculas com menor grau de polimerização, o que afeta diversas propriedades da celulose (viscosidade, massa molar, resistência, etc.). Nas reações de adição - os componentes químicos que proporcionam a ocorrência de reação com a celulose, em geral, são agentes de inchamento. Por esta razão, tais compostos também são chamados de compostos de inchamento [10].

A reação de adição se inicia pela quebra das ligações de hidrogênio, entre as cadeias adjacentes de celulose, no decorrer do fenômeno de inchamento que ocorre antes da entrada do novo grupo químico na estrutura celulósica no processo de modificação. Na estrutura intumescida, o reagente químico pode penetrar e propagar-se livremente, chegando a formar derivados de celulose relativamente homogêneos. Portanto, na modificação de celulose por reação de adição, é necessária uma concentração mínima do agente intumescedor. O valor desta concentração vai depender da natureza química do agente de adição, da temperatura em que a reação ocorre e da estrutura da cadeia da celulose a ser modificada. Se o agente de adição a penetrar entre as cadeias da celulose for muito volumoso, estas serão tão afastadas uma das outras que ocorrerá o que se denomina de separação das fibras. Isto é, a estabilidade do processo de modificação de celulose por reação de adição está condicionada à presença do agente intumescedor, contudo, a remoção deste não pode causar a regeneração da celulose [11].

As reações de substituição ocorrem nos grupos hidroxilas da celulose. Uma vez rompidas as ligações de hidrogênio entre as cadeias de celulose e conseguido o intumescimento intracristalino (reações de adição), os grupos hidroxilas presentes na cadeia celulósica são capazes de reagir como qualquer grupo hidroxila alifático. Se as fibras de celulose estão presentes em um meio que não favoreça seu intumescimento, as reações de substituição se limitarão às suas superfícies. Se as fibras de celulose estão em um meio que favoreça seu intumescimento, expondo suas superfícies internas, será substituído um número muito maior de grupos hidroxilas. Essa substituição nas hidroxilas da celulose resultante da inserção do agente modificante promove uma desorganização na sua estrutura, e, por conseguinte facilita a sua solubilização em meio aquoso.

A modificação da celulose, no presente estudo, se deu por reação de substituição e teve como proposta obter uma substância surfactante. Isto é, substância com molécula anfifílica, constituídas de uma porção hidrofóbica (apolar) e uma porção hidrofílica (polar). Essas substâncias atuam na superfície dos líquidos reduzindo-lhes a tensão superficial, comportamento físico-químico de grande interesse industrial. Contudo, uma substância surfactante quando em meio aquoso apresenta formação de espumas, característica que é indesejável quando se tem como foco a aplicação do produto em processo industrial de extração de petróleo. A espuma resulta de agrupamento de moléculas surfactantes e a sua estabilidade depende das propriedades dos grupos polar e apolar presentes na estrutura, essa polaridade para celulose de sisal está relacionada à presença do grupo hidroxila que quando não apresenta um grau de substituição significativo leva à formação de espuma. Deste modo, um dos desafios no presente estudo foi medir o grau de 
saponificação da celulose modificada que pode ser realizado pela determinação do número de hidroxila não substituída no processo de modificação [11].

O presente estudo trata da obtenção de substância surfactante a partir da modificação da celulose de sisal (Agave sisalana) por meio da obtenção de xantatos celulósicos e posterior modificação desses com álcool láurico.

\subsection{MATERIAL}

A celulose de sisal (Agave sisalana) empregada neste estudo foi doada pela fábrica SUZANO CELULOSE E PAPEL S.A. O álcool láurico, usado como modificante; ácido sulfúrico, como agente de sulfonação; hidróxido de sódio usado na desidroxilação da celulose de sisal, dissulfeto de carbono usado como finalizador de desidroxilação da celulose; éter etílico, como solvente na solução de sulfonação de álcool láurico com ácido sulfúrico. Todos os reagentes da marca VETEC. Resina de troca iônica doada pela FAFEN/SE empregada no processo de purificação do surfactante obtido.

\subsection{MÉTODOS}

\section{Mecanismo de obtenção do xantato celulósico}

O processo de xantatização da celulose de sisal foi realizado utilizando a concentração de $\mathrm{NaOH}$ 17,5\% (m/v), o que conferiu uma maior substituição das hidroxilas [12]. Para produção do xantato, a celulose de sisal foi submetida inicialmente a um processo de moagem com o auxílio de um moinho de bolas por um período de 48horas e, em seguida, a tratamento alcalino, na presença de solução de hidróxido de sódio $17,5 \%(\mathrm{~m} / \mathrm{v}$ ), por um período de 02 (duas) horas sob agitação mecânica. Para finalização do processo reacional, adicionou-se $2 \%(\mathrm{v} / \mathrm{v})$ de dissulfeto de carbono. O fluxograma da Figura 1 mostra de forma esquematizada os procedimentos empregados no processo de obtenção e modificação do xantato celulósico a partir da celulose de sisal. 


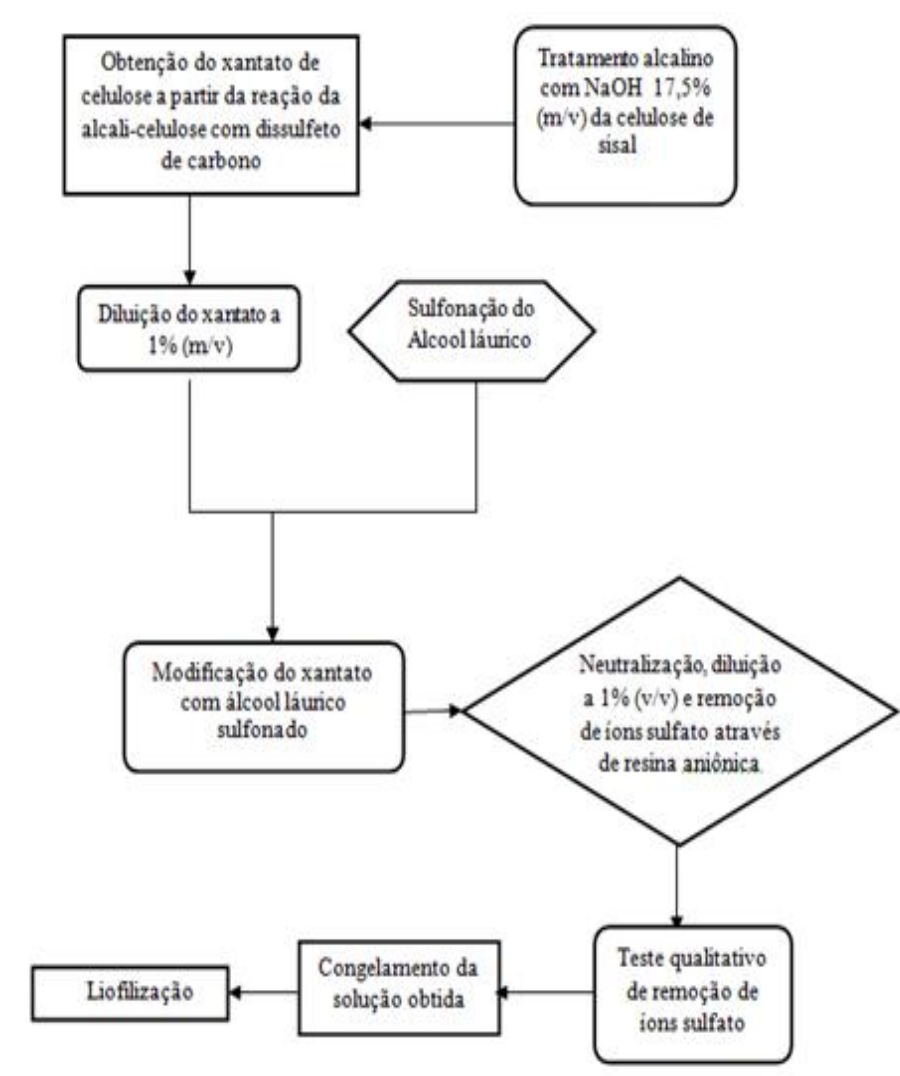

Figura 1: Fluxograma do processo de obtenção e modificação do xantato celulósico a partir da celulose de sisal (Agave sisalana)

Mecanismo de modificação da celulose de sisal a partir do xantato celulósico: O xantato celulósico obtido foi diluído em água deionizada a concentração de $1 \%(\mathrm{v} / \mathrm{v})$ e submetido a processo de modificação, em duas etapas, tendo como agente modificante o álcool láurico. $\mathrm{Na}$ Etapa 1, submeteu-se o álcool láurico a tratamento ácido na presença de ácido sulfúrico na temperatura ambiente, sob agitação mecânica, tendo como solvente o éter etílico, com a finalidade de introduzir o grupo sulfato abandonador. A Figura 2 mostra, de forma esquemática, o mecanismo do processo de reação realizado na Etapa 1.

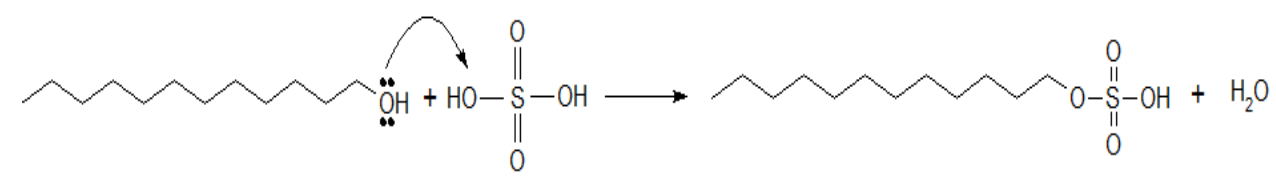

Figura 2: Representação esquemática do mecanismo de sulfonação do álcool láurico [13].

Na Etapa 2, o álcool láurico sulfonado foi adicionado à solução diluída de xantato celulósico $1 \%$ $(\mathrm{v} / \mathrm{v})$, onde através do grupo sulfato abandonador, presente no álcool láurico, foi introduzida a cadeia carbônica do modificador ao xantato, com liberação de sulfato de sódio. A Figura 3 mostra, de forma esquemática, o mecanismo proposto do processo de reação do xantato de celulose com o álcool láurico sulfonado (Etapa 2). 


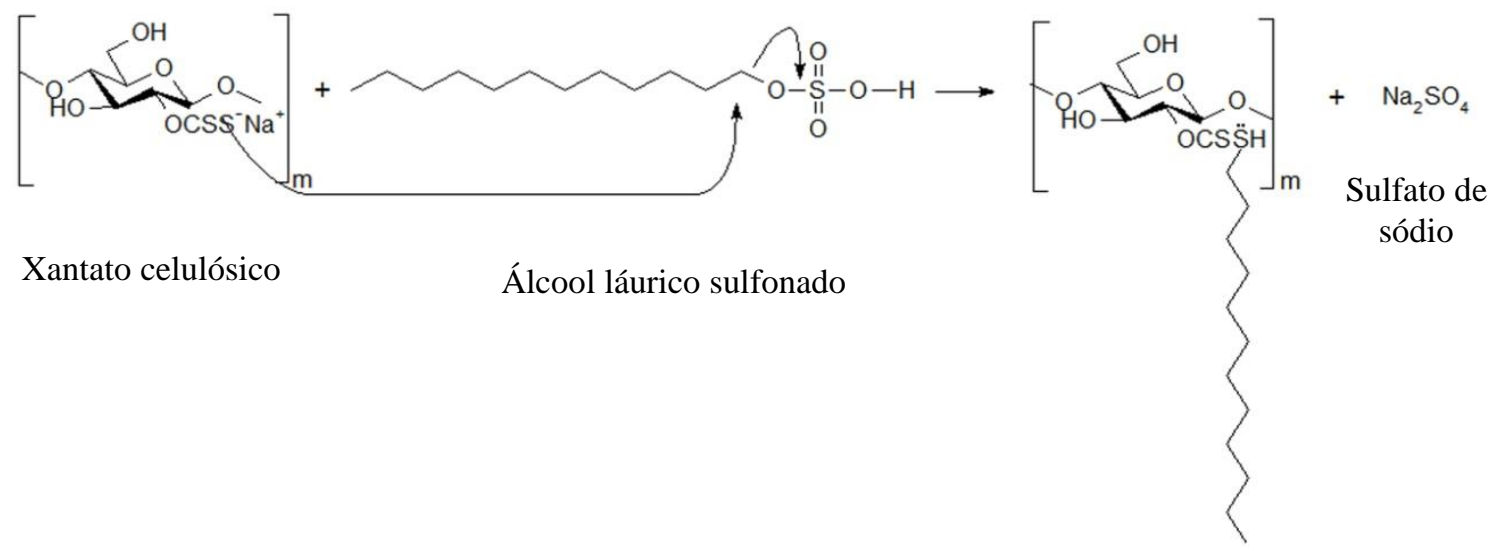

Éter de celulose

Figura 3: Representação esquemática do mecanismo proposto de reação de modificação da celulose a partir de xantato de celulose de sisal com álcool láurico.

Mecanismo de remoção de íons sulfato: $\mathrm{O}$ xantato de celulose, ao passar pelo processo de modificação proposto no presente estudo, libera o sal sulfato de sódio $\left(\mathrm{Na}_{2} \mathrm{SO}_{4}\right)$ conforme mostra a representação esquemática do mecanismo de reação de modificação da celulose apresentado na Figura 3.

A presença de íons sulfato em soluções aquosas, na presença de cálcio e magnésio, favorece a formação de sais insolúveis. Assim, para que a celulose modificada possa atuar de forma eficiente sem gerar subproduto indesejável, faz-se necessário a remoção de íons sulfato na finalização do processo de modificação da celulose.

A remoção do íon sulfato, presente na forma de sulfato de sódio, no processo em estudo, foi realizada por meio da adição da resina de troca iônica DOWEX MARATHON, doada pela FAFEN/SE e cedida pelo laboratório de química industrial do DEQ/UFS. Esta resina foi adicionada no meio reacional, no final do processo e, devido à sua capacidade de troca iônica, adsorveu o íon sulfato na sua superfície que foi removido do meio reacional por filtração.

A Equação Química 1 mostra, de forma esquemática, a reação de remoção do íon sulfato.

$$
\mathrm{Na}_{2} \mathrm{SO}_{4}+2 \mathrm{ROH} \rightarrow 2 \mathrm{RSO}_{4}^{2-}+2 \mathrm{NaOH}
$$

A verificação da eficiência do processo de remoção do íon sulfato foi realizada por método analítico qualitativo, por meio de teste titulométrico, de identificação da presença de sulfato, empregando como titulante solução de cloreto de bário $10 \%(\mathrm{~m} / \mathrm{v})$ em solução aquosa de $1 \%(\mathrm{v} / \mathrm{v})$ de celulose modificada, antes e após o tratamento de remoção de sulfato, visualizando a formação ou não de sulfato de bário, por meio da turvação do meio titulado. A Equação Química 2 mostra de forma simplificada a possível formação de sulfato de bário no sistema em estudo.

$$
\begin{aligned}
& \mathrm{BaCl}_{2}+\mathrm{Na}_{2} \mathrm{SO}_{4} \rightarrow \mathrm{BaSO}_{4}+2 \mathrm{NaCl} \\
& \begin{array}{cccc}
\begin{array}{c}
\text { Cloreto de } \\
\text { Bário }
\end{array} & \begin{array}{c}
\text { Sulfato de } \\
\text { sódio }
\end{array} & \begin{array}{c}
\text { Sulfato de } \\
\text { Bário }
\end{array} & \begin{array}{c}
\text { Cloreto de } \\
\text { sódio }
\end{array}
\end{array}
\end{aligned}
$$

Separação da celulose modificada do meio reacional- A separação da celulose modificada do meio reacional ocorreu por processo de liofilização que consistiu em primeiro congelar todo o 
material do meio reacional, em seguida submeter a fase aquosa sólida à sublimação sob pressão reduzida, finalizando o processo com a remoção da fase aquosa incongelável (adsorvida na celulose modificada) por dessorção através de secagem à vácuo. Obteve-se assim, como produto final, a celulose modificada na forma de pó [14].

Para a realização do congelamento da amostra utilizou-se o ultrafreezer da marca Liotop, modelo UFR 30. A sublimação e a dessorção, respectivamente, da fase aquosa congelada e adsorvida na celulose modificada se deu por meio do equipamento liofilizador da marca Liotop, modelo L101 à pressão reduzida de $250-500 \mu \mathrm{mHg}$ e na temperatura de $-50^{\circ} \mathrm{C}$.

\subsection{CARACTERIZAÇÃO DO PRODUTO OBTIDO}

Caracterização por Espectroscopia de absorção na região do Infravermelho com transformada de Fourier FTIR - As análises de espectroscopia foram feitas em um equipamento da marca Thermo scientific, modelo Nicolet iS10, com o objetivo de averiguar a incorporação do agente modificante -álcool láurico- no xantato de celulose de sisal.

Avaliação do grau de saponificação - Foi realizada de forma qualitativa observando comparativamente o volume de espuma formado quando da dissolução em meio aquoso dos xantatos de celulose de sisal e de celulose microcristalina comercial, modificados com álcool láurico.

Calorimetria Exploratória Diferencial (DSC) - É uma técnica que mede as temperaturas e o fluxo de calor associado às transições dos materiais em função da temperatura e do tempo. Tais medidas fornecem informações qualitativas e quantitativas sobre mudanças físicas e químicas que envolvem processos endotérmicos (absorção de calor), exotérmicos (evolução de calor) ou mudanças na capacidade calorífica. Neste estudo, análises de DSC foram realizadas em um equipamento da marca NETZSCH modelo 200 F3 em amostras de celulose de sisal bruta e xantato de celulose modificada com álcool láurico a fim de avaliar a estabilidade térmica do produto obtido.

Análise de Porosidade do xantato de celulose de sisal modificado - A análise da porosidade do xantato de celulose modificado foi realizada em um analisador de porosidade através da técnica B.E.T. (Brunauer-Emmett-Teller), com o objetivo de avaliar a possibilidade de sua dispersão em meio aquoso.

\section{RESULTADOS E DISCUSSÃO}

As Figuras 4 (a, b) mostram, respectivamente, a celulose de sisal antes e após a modificação, após a liofilização. Observa-se que o material obtido apresenta-se com um aspecto de pó fino de cor branca.

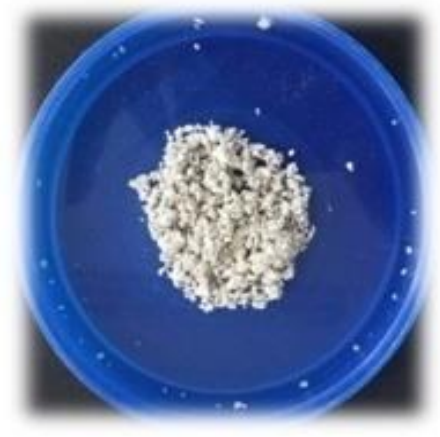

(a)



(b)

Figura 4: Amostra da celulose de sisal antes do processo de modificação (a) e modificada após o processo de liofilização (b). 
As Figuras 5 a e 5b, respectivamente, mostram qualitativamente o grau de saponificação entre amostras de xantatos de celulose comercial microcristalina e de sisal modificados com álcool láurico. Observa-se que a celulose microcristalina comercial apresenta um maior volume espuma que pode ser atribuído à menor substituição de hidroxilas presentes na sua microestrutura pelo agente modificante, devido ao seu alto empacotamento [12].

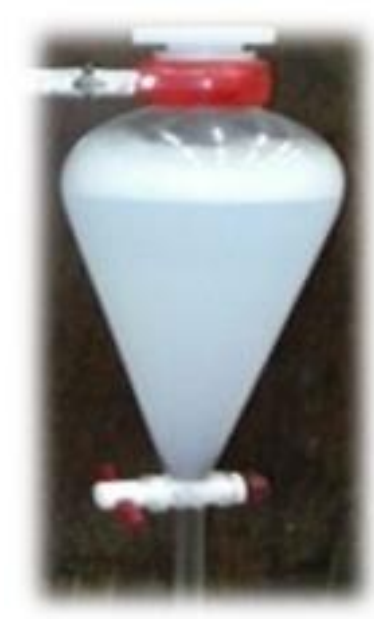

(a)

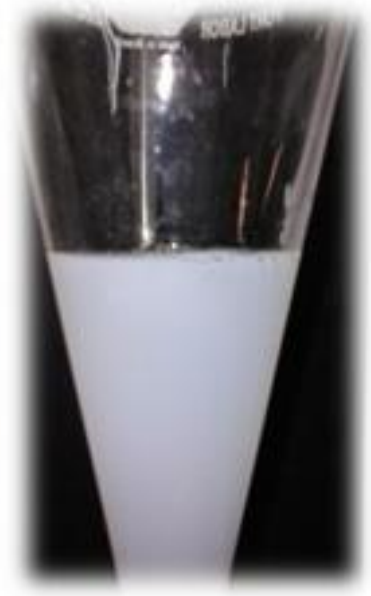

(b)

Figura 5: Fotografia do xantato celulósico modificado a partir da celulose microcristalina comercial (a) e a partir de celulose de sisal (Agave sisalana) (b).

Purificação do produto obtido: Durante o processo de modificação de celulose a partir de xantato ocorre a formação de sulfato de sódio, de difícil remoção direta, por encontrar-se dissolvido no meio aquoso do processo. Por se tratar de uma substância indesejável no processo de extração de petróleo, setor final objeto de uso do produto, a remoção do íon sulfato foi realizado por filtração em meio granular formado por resina de troca iônica; cuja remoção do íon sulfato do produto obtido em meio filtrante de resina de troca iônica mostrou ser eficiente.

A verificação da remoção do íon sulfato se deu pelo processo adição de cloreto de bário seguida de observação de formação, ou não, de precipitado de sulfato de bário. A Figura 6 mostra o comportamento da solução aquosa na concentração de 1/100 (v/v) do produto obtido após adição de cloreto de bário, respectivamente (6a) solução após passar no meio filtrante e (6b) antes de passar no meio filtrante de resina de troca iônica. Observa-se na Figura $6 \mathrm{~b}$ a presença de precipitação do sulfato de bário que torna o meio translúcido.

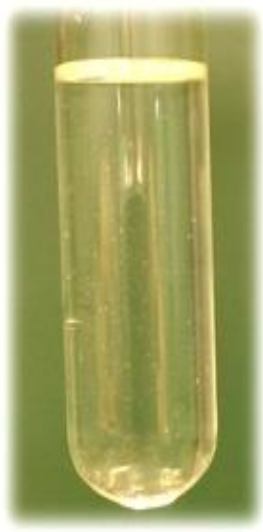

(a)

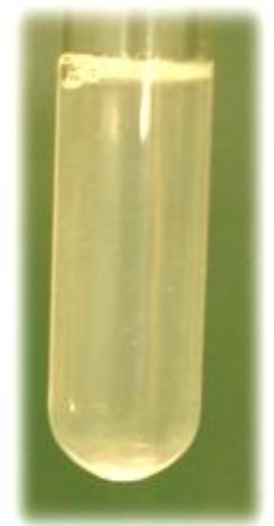

(b)

Figura 6: Solução aquosa de celulose de sisal modificada com adição de cloreto de bário, após o tratamento de remoção do íon sulfato(a) e solução aquosa de celulose de sisal antes da remoção do íon sulfato $(b)$. 


\section{Caracterização química da celulose de sisal modificada a partir do xantato por FT-IR}

A Figura 7 mostra os resultados da espectroscopia na região do infravermelho (FT-IR) para a celulose bruta, modificada e para o agente modificante. Na análise comparativa dos espectros observa-se um deslocamento da banda de número de onda $1215 \mathrm{~cm}^{-1}$ característico da formação de tiocarbonila $(\mathrm{C}=\mathrm{S})$. A banda que aparece em torno de $2918 \mathrm{~cm}^{-1}$ está relacionada às ligações C-H presentes em grande quantidade no álcool láurico utilizado como modificante e que aparece na celulose de sisal após sofrer modificação [15].

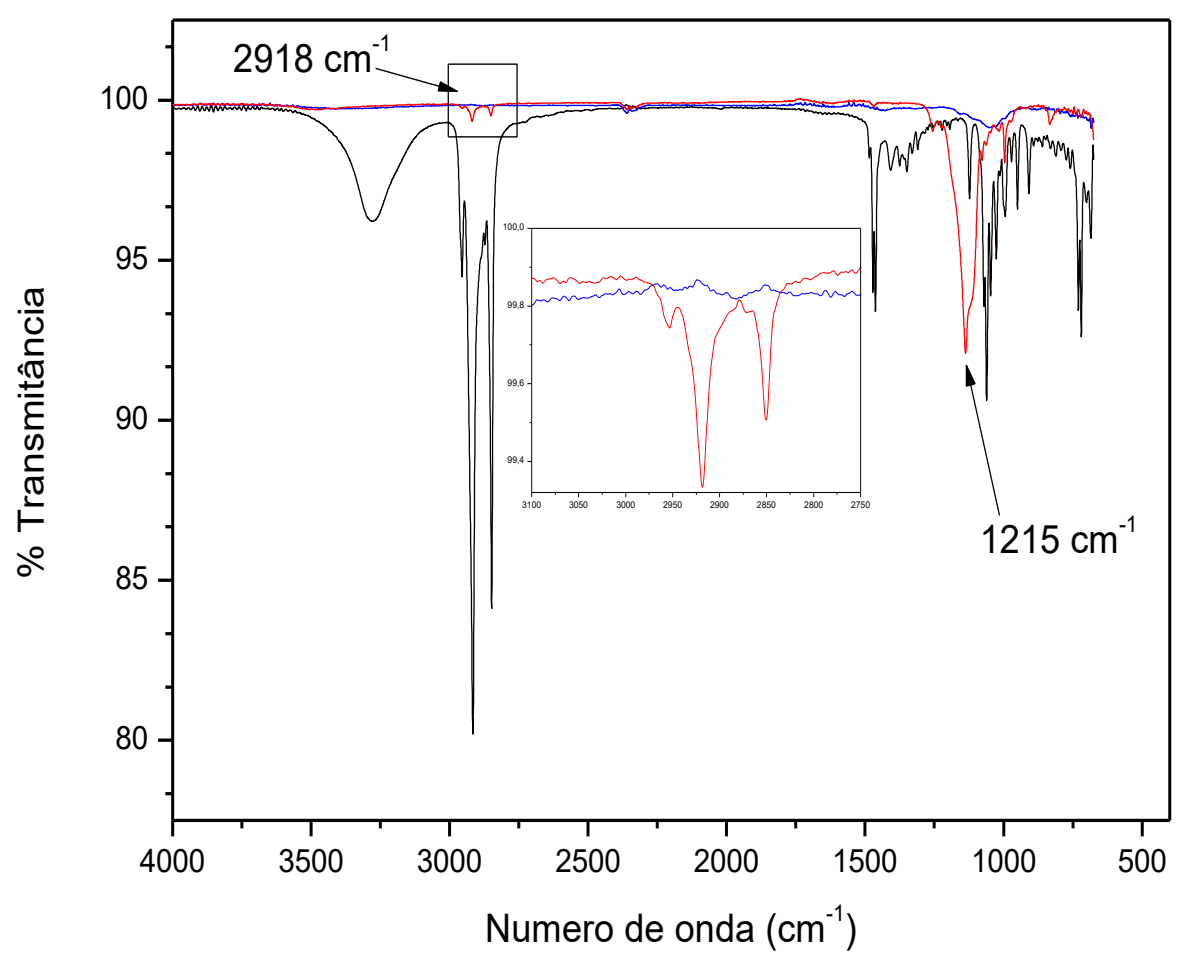

Figura 7: Espectro de infravermelho para celuloses: (a) ( - celulose de sisal bruta, (b) (-) celulose de sisal modificada com sulfato, (c) (—) celulose de sisal modificada sem sulfato.

A caracterização por FT-IR da celulose de sisal modificada após tratamento de remoção dos íons sulfato é apresentada na Figura 8. Observa-se que mesmo após o processo de remoção do sulfato de sódio, através da utilização da resina, a banda das ligações C-H que aparece em torno de $2918 \mathrm{~cm}^{-1}$, presente no álcool láurico utilizado como agente modificante, permanece presente na celulose de sisal após sofrer modificação assim como a banda referente à formação da tiocarbonila $(\mathrm{C}=\mathrm{S})$ em $1215 \mathrm{~cm}^{-1}$ proveniente da xantatização. Embora seja verificada a presença de tais bandas, não foi possível através da técnica utilizada observar a ligação da cadeia alifática do álcool com a celulose xantatizada, conforme mecanismo proposto apresentado na Figura 3. 


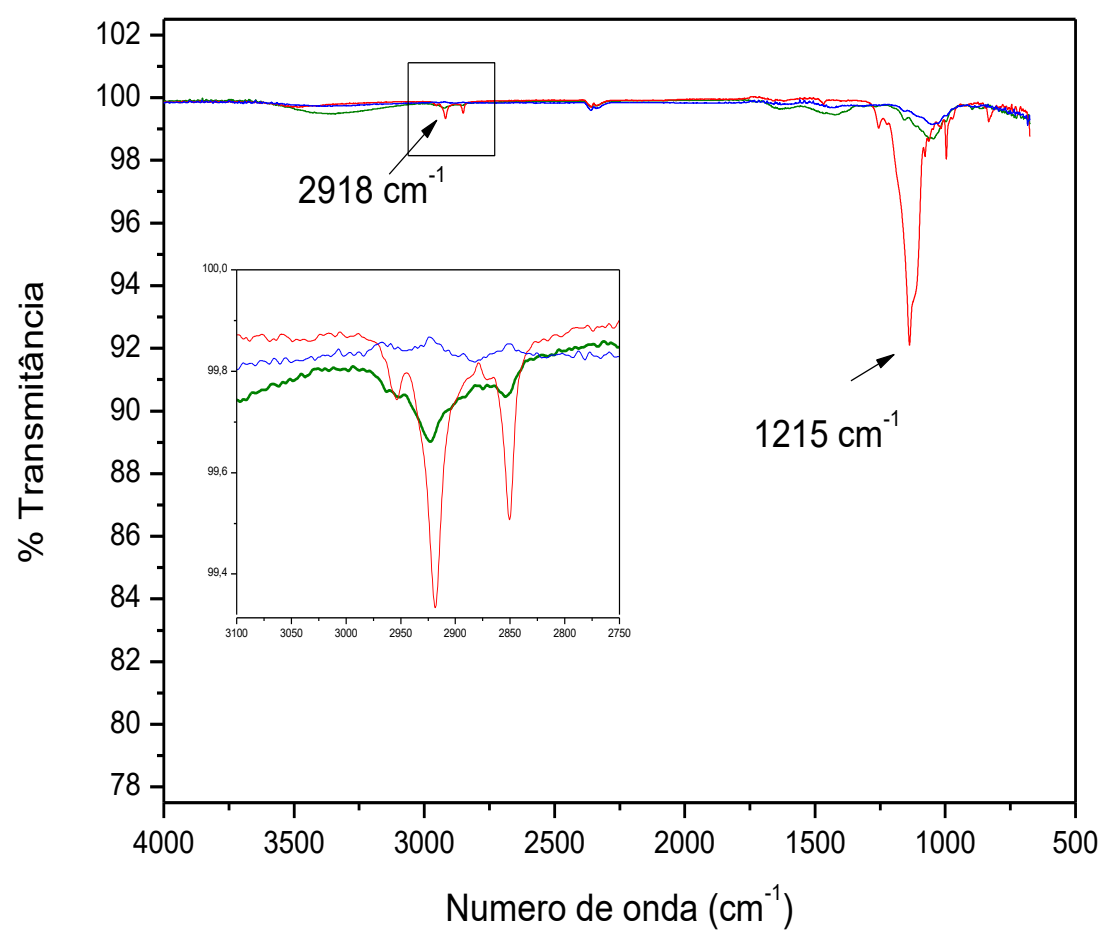

Figura 8: Espectro de infravermelho para celuloses: (a) (_ ) celulose de sisal bruta (b) ( — ) celulose de sisal modificada com sulfato (c) (-) celulose de sisal modificada sem sulfato.

Caracterização térmica da celulose de sisal modificada a partir de xantato de celulose por Calorimetria Exploratória Diferencial (DSC)

A Figura 9 mostra as curvas de DSC para a celulose de sisal bruta e modificada (na forma de xantato) com álcool láurico. Observa-se que a celulose bruta apresenta um evento endotérmico na temperatura de $100^{\circ} \mathrm{C}$ atribuído à evaporação de água presente na amostra. Observa-se também um evento exotérmico entre 300 e $375^{\circ} \mathrm{C}$ que pode está relacionado ao processo de oxidação da celulose bruta, como também observado por Martin et al.[16]. Com relação ao xantato de celulose de sisal modificado com álcool láurico, observa-se um evento endotérmico entre 225 e $250^{\circ} \mathrm{C}$ que pode está relacionado ao processo de dissociação do agente modificante, álcool láurico [17]. Observa-se ainda que nas curvas de DSC que tanto a celulose de sisal pura quanto o xantato de celulose de sisal modificado com álcool láurico apresentam declive endotérmico a partir da temperatura de $350^{\circ} \mathrm{C}$ que pode está relacionado à degradação de ambas as amostras [17-20]. 


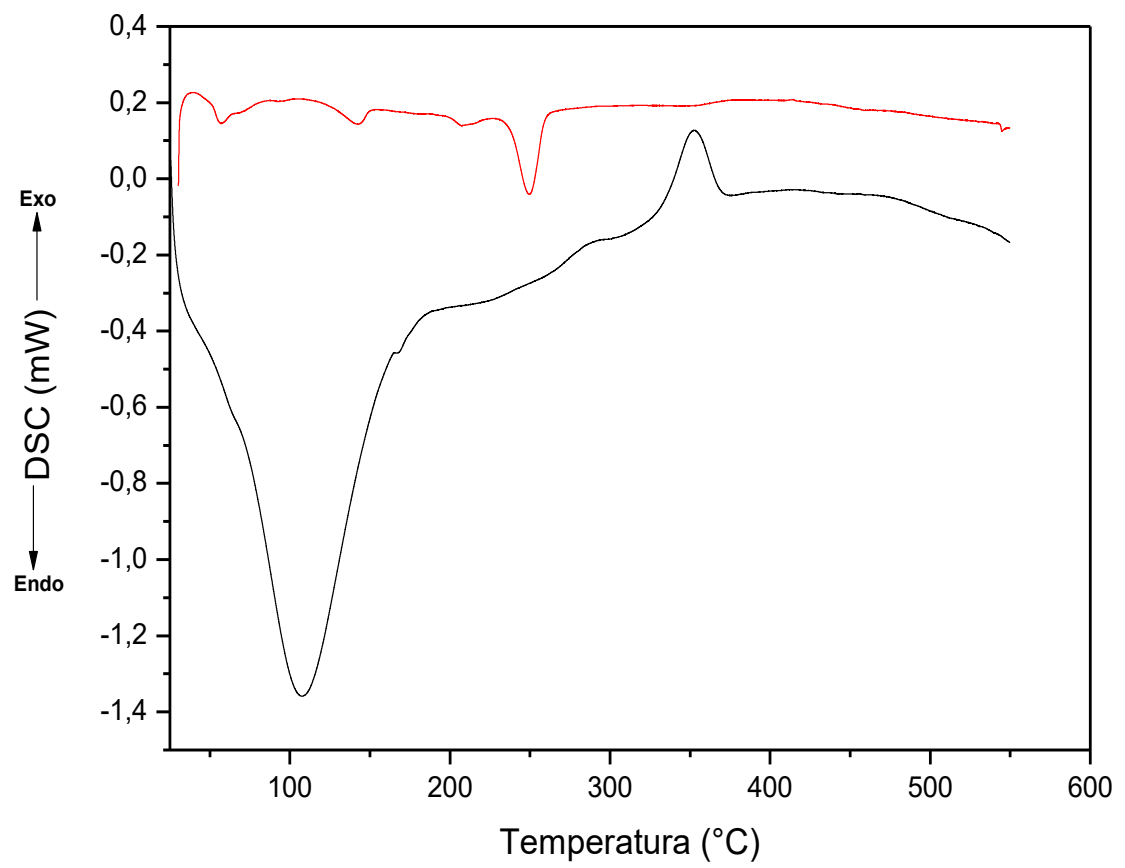

Figura 9: Termograma para celuloses: (a) (—) celulose de sisal bruta, (b) (—) celulose de sisal modificada sem sulfato

\section{Caracterização física de medida de porosidade por meio da técnica B.E.T}

A análise consistiu em determinar o raio do poro da celulose de sisal modificada com álcool láurico cujo valor encontrado foi de $0,86 \mathrm{~nm}$. Sabendo que o raio da molécula de água no estado líquido é de $0,14 \mathrm{~nm}$ [21], o produto obtido apresenta características físicas favoráveis à dispersão em meio aquoso.

Caracterização da morfologia da celulose de sisal bruta e modificada a partir de xantato de celulose por microscopia ótica

A Figura 10 (a-d) mostra imagens de microscopia ótica obtidas por meio do equipamento USB Digital Microscope 20x-800x, com ampliação de 20x e 400x, da celulose de sisal bruta e do xantato de celulose de sisal modificado. Observa-se que a amostra bruta apresenta uma morfologia grosseira enquanto que a amostra de xantato de celulose modificada apresenta uma morfologia fina. 


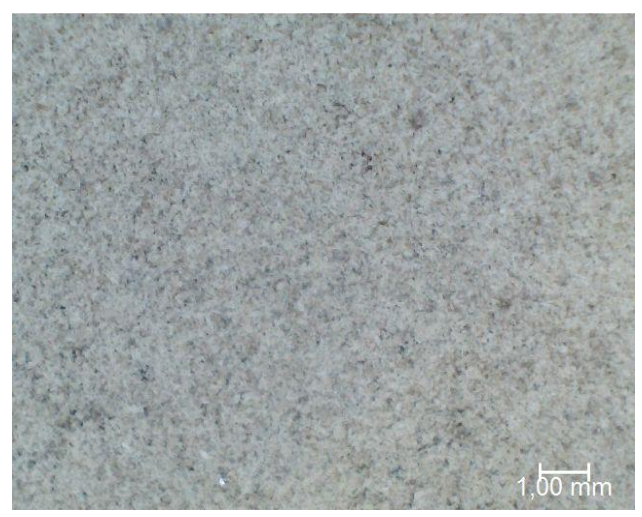

(a)

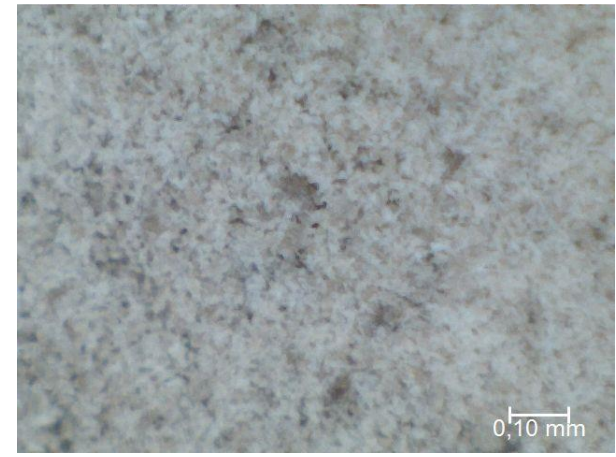

(c)

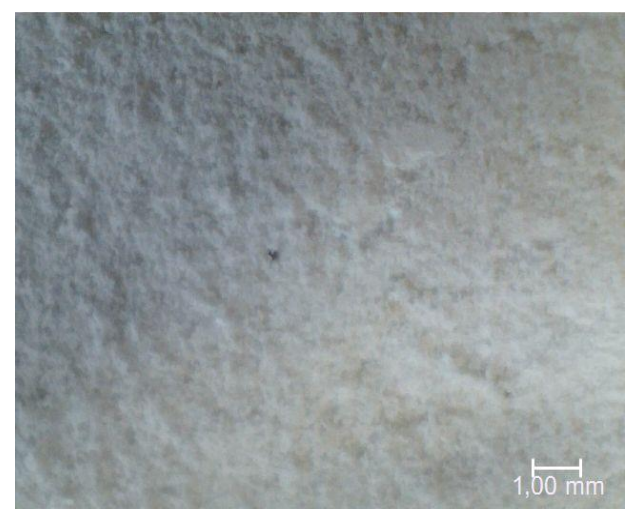

(b)

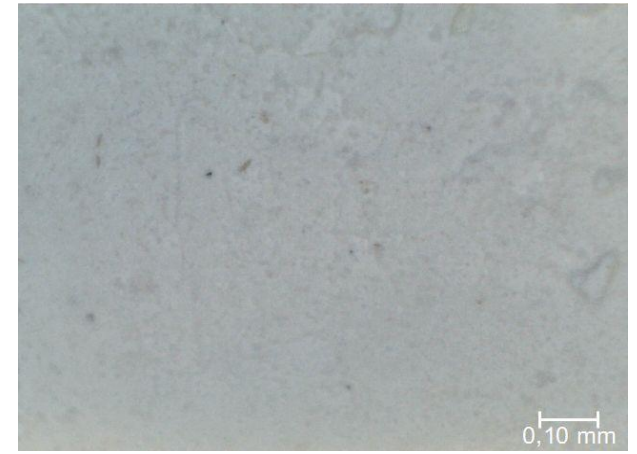

(d)

Figura 10: Microscopia ótica da celulose de sisal bruta e de xantato de celulose sisal modificado com ampliação de 20x (a,b) e com ampliação de 400x (c,d).

\section{CONCLUSÃO}

A partir das análises realizadas, concluiu-se que é possível obter substância surfactante com baixa formação de espuma em virtude da substituição das hidroxilas presentes na celulose pelo agente modificante álcool láurico a partir de modificação de celulose. Contudo é preciso inicialmente passar a celulose por um processo de xantatização para tornar a sua estrutura suscetível a modificação que atribua ao material à característica de surfactante desejada. Devido às características de pouca formação de espumas e de boa dispersão em meio aquoso, o produto obtido pode ser aplicado na indústria de extração de petróleo.

\section{AGRADECIMENTOS}

Os autores agradecem ao CNPq pela concessão da bolsa de mestrado, processo nº133910/2013-0e ao Programa de Pós-Graduação em Engenharia Química da Universidade Federal de Sergipe (PEQ/UFS) pela oportunidade de realização da pesquisa, à SUZANO Papel e Celulose, ao Laboratório de Química Industrial/DEQ-UFS e à Petrobras/UO-SEAL, pelos materiais utilizados neste estudo. 


\section{REFERÊNCIAS BIBLIOGRÁFICAS}

1. Li S, Zhang S, Wang X. Fabrication of superhydrophobic cellulose-based materials through a solutionimmersion process. Langmuir. 2008 Abr;24(10):5585-5590, doi: 10.1021/la800157t.

2. Liu CF, Zhang AP, Li WY, Yue FX, Sun RC. Homogeneous modification of cellulose in ionic liquid with succinic anhydride using $n$-bromosuccinimide as a catalyst. J. Agric. Food Chem. 2009 Mar;57:18141820, doi: 10.1021/jf803097k.

3. Deng W, Zhang Q, Wang Y. Catalytic transformations of cellulose and cellulose-derived carbohydrates into organic acids. Catal. Today. 2014 Out;234(1):31-41, doi:10.1016/j.cattod.2013.12.041.

4. Liu, CF, Zhang, A.P, Li WY. Yue, FX, Sun, RC. Succinolation of cellulose catalyzed with iodine in ionic liquid. Ind Crops Prod. 2010 Fev; 31(2):363-369, doi: 10.1016/j.indcrop.2009.12.002

5. Jia X, Chen Y, Shi C, Ye Y, Wang P, Zeng X, Wu T. Preparation and Characterization of Cellulose Regenerated from Phosphoric Acid. J. Agric. Food Chem. 2013 Nov;61(50):12405-12414, doi: $10.1021 / \mathrm{jf} 4042358$.

6. Klemm D, Heublein B, Fink HP, Bohn A. Cellulose: fascinating biopolymer and sustainable raw material. Angew Chem. Int. Ed. Engl. 2005 Mai;44(22):3358-3393, doi: 10.1002/anie.200460587.

7. Silva R, Haraguchi SK, Muniz EC, Rubira AF. Aplicações de fibras lignocelulósicas na química de polímeros e em compósitos. Quim. Nova. 2009 Mar;32(3): 661-671, doi: 10.1590/S010040422009000300010.

8. Li WY, Jin XB, Liu CF, Sun RC, Zhang AP, Kennedy JF. Homogeneous modification of cellulose with succinic anhydride in ionic liquid using 4- dimethylaminopyridine as a catalyst. Carbohydr. Polym. 2009 Out;78(3):389-395, doi:10.1016/j.carbpol.2009.04.028.

9. Jin $\mathrm{H}$, Zha C, Gu L. Direct dissolution of cellulose in $\mathrm{NaOH} /$ thiouréia/uréia aqueous solution. Carbohidr. Res., 2007 May;342(6):851-858, doi: 10.1016/j.carres.2006.12.023.

10. Gallego R, Arteaga JF, Valencia C, Franco JM. Chemical modification of methyl cellulose with hdmi to modulate the thickening properties in castor oil. Cellulose. $2013 \mathrm{Fev}$;20(1):495-507, doi: 10.1007/s10570012-9803-4.

11. Xiao D, Yang F, Han H, Liu Z, Zhang S, Li G. Preparation of oligosaccharide surfactant based on cotton cellulose and application in hydrophilic modification of docetaxel. Colloids and Interface Sci. Commun. 2015 Jan;4:10-13, doi:10.1016/j.colcom.2015.04.002.

12. Hirano S, Usuta A, and Midorikawa T. Novel fibers of iv-acylchitosan and its cellulose composite prepared by spinning their aqueous xanthate solutions. Carbohydr. Polym. 1997 Mai;33(1):1-14, doi: 10.1016/S0144-8617(97)00039-8.

13. Volhard KPC, Neil, ES. Química orgânica: estrutura e função. 4 edição Porto Alegre: Bookman, 2004.

14. Pessoa AJr, Kilikian BV. Purificção de produtos biotecnológicos. 1 edição. 2005 Barueri-SP. 404p.

15. Silverstein RM, Webster FX, Kiemle DJ. Identificação espectrométrica de compostos orgânicos, Ed.; LTC, Rio de Janeiro, 2007, Vol. único, 508 p..

16. Martin RA, Martins MA, Mattoso LHC, Silva ORRF. Caracterização química e estrutural de fibra de sisal da variedade Agave sisalana. Polímeros. 2009 Set;19(1):40-46, doi: 10.1590/S010414282009000100011.

17. Ma Y, Zong J, Li W, Chen L, Tang X, Han N, Wang J, Zhang X. Synthesis and characterization of thermal energy storage microencapsulated n-dodecanol with acrylic polymer shell. Energy. 2015 Mai;87: 86-94, doi: 10.1016/j.energy.2015.04.096.

18. Santos ML, Lima OJ, Nassar EJ, Ciuffi KJ, Calefi PS. Estudo das condições de estocagem do bagaço de cana-de-açúcar por análise térmica. Quim. Nova. Vol. 2011 Jan;34(3):507-511.

19. Zeng L, Meng P. Preparation, characterization of corn stalk xanthates and its feasibility for Cd (II) removal from aqueous solution. J. Taiwan Inst. Chem. E. 2016;58:391-400, doi:10.1016/j.jtice.2015.06.017.

20. Srivastava A, Mandal P, Kumar R. Solid state thermal degradation behaviour of graft copolymers of carboxymethyl cellulose with vinyl monomers. Int. J. Biol. Macromolec. 2016 Mar;87:357-365, doi: 10.1016/j.ijbiomac.2016.03.004.

21. Libardi PL. Dinâmica da água nos solos. Ed.; EDUSP, São Paulo, 2005, 335 p. 